Revista Brasileira de Agricultura Irrigada v.13, no.1, p. 3212 - 3225, 2019

ISSN 1982-7679 (On-line)

Fortaleza, CE, INOVAGRI - http://www.inovagri.org.br

DOI: $10.7127 /$ rbai.v13n100960

Protocolo 960.19-01/06/2018 Aprovado em 01/04/2019

\title{
CULTIVO DE RÚCULA EM FIBRA DE COCO UTILIZANDO SOLUÇÃO NUTRITIVA SALINIZADA ENRIQUECIDA COM NITRATO DE POTÁSSIO
}

Carla Jamile Xavier Cordeiro ${ }^{1}$, José de Souza Leite $\mathrm{Neto}^{2}$, Mychelle Karla Teixeira de Oliveira ${ }^{3}$, Francisco Adênio Teixeira Alves ${ }^{4}$, Francisco Aparecido da Costa Miranda ${ }^{5}$, Francisco de Assis de Oliveira $^{6}$

\section{RESUMO}

A qualidade da água utilizada no preparo da solução nutritiva é de grande importância para obter êxito no cultivo hidropônico. Objetivou-se com este trabalho avaliar o efeito do enriquecimento da solução nutritiva salinizada com nitrato de potássio na cultura da rúcula cultivada em fibra de coco. Utilizou-se o delineamento inteiramente casualizado, analisando o desenvolvimento de duas cultivares de rúcula (Cultivada e Folha Larga) fertirrigadas com quatro soluções nutritivas [S1 - Solução nutritiva padrão; $\mathrm{S} 2$ - Solução nutritiva padrão + $\mathrm{NaCl}\left(3,5 \mathrm{dS} \mathrm{m}^{-1}\right) ; \mathrm{S} 3-\mathrm{S} 2+50 \%$ de $\mathrm{KNO}_{3} ; \mathrm{S} 2-100 \%$ de $\left.\mathrm{KNO}_{3}\right]$, em esquema fatorial 2 x 4, com três repetições. As plantas foram avaliadas aos 37 dias após a semeadura quanto às seguintes variáveis: altura, número de folhas, área foliar, massa fresca da parte aérea, massa seca da parte aérea, área foliar específica e suculência foliar. As duas cultivares de rúcula cultivadas em fibra de coco foram afetadas negativamente pelo uso de água salina no preparo da solução nutritiva, entretanto a cultivar Cultivada apresentou maior tolerância à salinidade quanto as variáveis área foliar, massa fresca da parte aérea e massa seca da parte aérea. O enriquecimento da solução nutritiva salina com nitrato de potássio amenizou o efeito da salinidade apenas na cultivar Folha Larga, mas não interferiu na resposta da cultivar Cultivada à salinidade. No cultivo de rúcula, cultivar Folha Larga, em

\footnotetext{
${ }^{1}$ Graduanda em Agronomia, Departamento de Ciências Agronômicas e Florestais, Universidade Federal Rural do SemiÁrido, Mossoró, Brasil, Av. Francisco Mota, 572 - Bairro Costa e Silva, CEP: 59.625-900. E-mail:

carlajamile0808@gmail.com

${ }^{2}$ Engenheiro Agrônomo, Departamento de Ciências Agronômicas e Florestais, Universidade Federal Rural do Semi-Árido, Mossoró, Brasil, Av. Francisco Mota, 572 - Bairro Costa e Silva, CEP: 59.625-900. E-mail: netoleiteneto@ yahoo.com.br ${ }^{3}$ Doutora em Fitotecnia, Departamento de Ciências Agronômicas e Florestais, Universidade Federal Rural do Semi-Árido, Mossoró, Brasil, Av. Francisco Mota, 572 - Bairro Costa e Silva, CEP: 59.625-900. E-mail: mymykar@gmail.com

${ }^{4}$ Engenheiro Agrônomo, Departamento de Ciências Agronômicas e Florestais, Universidade Federal Rural do Semi-Árido, Mossoró, Brasil, Av. Francisco Mota, 572 - Bairro Costa e Silva, CEP: 59.625-900. E-mail: adenio.a@ hotmail.com ${ }^{5}$ Engenheiro agrônomo, Departamento de Ciências Agronômicas e Florestais, Universidade Federal Rural do Semi-Árido, Mossoró, Brasil, Av. Francisco Mota, 572 - Bairro Costa e Silva, CEP: 59.625-900. E-mail: fcidcm@ bol.com.br ${ }^{6}$ Prof. Adjunto, Departamento de Ciências Agronômicas e Florestais, Universidade Federal Rural do Semi-Árido, Mossoró, Brasil, Av. Francisco Mota, 572 - Bairro Costa e Silva, CEP: 59.625-900. E-mail: thikaoamigao@ufersa.edu.br
} 
fibra de coco utilizando solução salina deve-se aumentar a concentração de $\mathrm{KNO}_{3}$ em $100 \%$ em relação à concentração padrão.

Palavras-chave: Eruca sativa Miller, cultivo sem solo, salinidade

\title{
ARUGULA CULTIVATION IN COCONUT FIBER USING SALINE NUTRIENT SOLUTION ENRICHED WITH POTASSIUM NITRATE
}

\begin{abstract}
The quality of water used to prepare the nutrient solution is of great importance to achieve success in hydroponic cultivation. The present study aimed to evaluate the effect of the enrichment of a saline nutrient solution with potassium nitrate on the arugula crop grown in coconut fiber. A completely randomized design was used to analyze the development of two arugula cultivars ('Cultivada' and 'Folha Larga') fertigated with four nutrient solutions [S1 - Standard nutrient solution; S2 - Standard nutrient solution $+\mathrm{NaCl}\left(3.5 \mathrm{dS} \mathrm{m} \mathrm{m}^{-1}\right) ; \mathrm{S} 3-\mathrm{S} 2+50 \%$ of $\mathrm{KNO}_{3} ; \mathrm{S} 2-100 \%$ of $\mathrm{KNO}_{3}$ ], in $2 \times 4$ factorial scheme, with three replicates. Plants were evaluated at 37 days after sowing for the following variables: height, number of leaves, leaf area, shoot fresh matter, shoot dry matter, specific leaf area and leaf succulence. Both arugula cultivars grown in coconut fiber were negatively affected by the use of saline water to prepare the nutrient solution, but the cultivar 'Cultivada' was more tolerant to salinity in terms of leaf area, shoot fresh matter and shoot dry matter. Enrichment of saline nutrient solution with potassium nitrate mitigated the effect of salinity only on the cultivar 'Folha Larga' and did not interfere with the response of the cultivar 'Cultivada' to salinity. In the cultivation of arugula, cultivar 'Folha Larga', in coconut fiber using saline solution the concentration of $\mathrm{KNO}_{3}$ should be increased by $100 \%$ compared to the standard concentration.
\end{abstract}

Keywords: Eruca sativa Miller, soilless, salinity

\section{INTRODUÇÃO}

A rúcula (Eruca sativa Miller) é uma hortaliça folhosa herbácea pertencente à família Brassicaceae, sendo consumida principalmente na forma de salada. Seu cultivo é realizado predominantemente em condições de campo, mas já vem ganhando espaço no cultivo protegido, principalmente em hidroponia. A qualidade da água utilizada no preparo da solução nutritiva, principalmente quanto à condutividade elétrica, é fator chave para se obter êxito na produção de hortaliças, pois o uso de água salina pode provocar redução no crescimento das plantas (SANTOS et al., 2012; JESUS et al., 2015; OLIVEIRA et al., 2013).

A redução no desenvolvimento da rúcula sob estresse salino ocorre devido a redução do potencial osmótico da solução nutritiva, tendo como consequência, alterações fisiológicas na transpiração, condutância estomática e na taxa de fotossínteses líquida (HNILIČKOVÁ et al., 2017).

Outra razão para a redução no crescimento das plantas submetidas à salinidade está relacionada ao efeito específico dos íons tóxicos como $\mathrm{Na}^{+}$e $\mathrm{Cl}^{-}$, que entram no fluxo de transpiração e, eventualmente, causam injúrias nas folhas, reduzindo o crescimento ou influenciando negativamente na absorção de íons essenciais, como $\mathrm{K}^{+}, \mathrm{NO}_{3}{ }^{-}, \mathrm{Ca}^{2+}$ e $\mathrm{Mg}^{2+}$ (PÉREZ-LÓPEZ et al. 2014; LIRA et al., 2015; COVA et al., 2017).

O aumento na concentração de potássio na solução nutritiva pode reduzir a razão $\mathrm{Na}^{+} / \mathrm{K}^{+}$, aumentando assim a tolerância das plantas à salinidade (TAMMAM et al., 2008), mas ainda são escassos estudos nesta temática. 


\section{CULTIVO DE RÚCULA EM FIBRA DE COCO UTILIZANDO SOLUÇÃO NUTRITIVA SALINIZADA ENRIQUECIDA COM NITRATO DE POTÁSSIO}

Diante do exposto, o objetivo desse trabalho foi avaliar o comportamento das duas cultivares de rúcula cultivadas em fibra de coco e fertigadas com soluções nutritivas salinizadas enriquecidas com nitrato de potássio.

\section{MATERIAL E MÉTODOS}

O experimento foi desenvolvido nos meses de março e abril de 2017, em casa de vegetação localizada no setor experimental do Departamento de Ciências Agronômicas e Florestais, Centro de Ciências Agrárias, da Universidade Federal Rural do Semi-Árido (UFERSA) em Mossoró, RN (5 $5^{\circ} 12^{\prime}$ 04” S; $37^{\circ}$ 19' 39" W; altitude de $18 \mathrm{~m}$ ). A pesquisa foi realizada seguindo o delineamento estatístico inteiramente casualizado, em esquema fatorial 2 $\mathrm{x}$ 4, com três repetições. Os tratamentos resultaram da combinação de duas cultivares de rúcula (Cultivada e Folha Larga) com quatro soluções nutritivas [S1-Solução nutritiva padrão; S2-solução nutritiva salinizada $(3,5 \mathrm{dS}$ $\left.\mathrm{m}^{-1}\right)$; S3-solução nutritiva salinizada $(3,5 \mathrm{dS} \mathrm{m}$ ${ }^{1}$ ) e enriquecida com $\mathrm{KNO}_{3}(50 \%)$; S4-solução nutritiva salinizada $\left(3,5 \mathrm{dS} \mathrm{m}^{-1}\right)$ enriquecida com $\left.\mathrm{KNO}_{3}(100 \%)\right]$.

Os níveis salinos utilizados representam a amplitude das salinidades de água subterrâmenas na região onde foi desenvolvimento o experimento (MEDEIROS et al., 2003).

$\begin{array}{lrrrr} & \text { A água } & \text { utilizada } & \text { no } & \text { preparo } \\ \text { das soluções } & \text { nutritivas } & \text { foi } & \text { obtida } \\ \text { no sistema } & \text { de } & \text { abastecimento } & \text { da } \\ \text { UFERSA, } & \text { cujas } & \text { características } & \text { são } \\ \text { apresentadas na Tabela } 1 . & & & \end{array}$

Tabela 1. Caracterização química da água utilizada no preparo das soluções nutritivas para o cultivo de rúcula em fibra de coco.

\begin{tabular}{cccccccccc}
\hline $\mathrm{pH}$ & $\mathrm{CE}$ & $\mathrm{K}^{+}$ & $\mathrm{Na}^{+}$ & $\mathrm{Ca}^{2++}$ & $\mathrm{Mg}^{2}$ & $\mathrm{Cl}^{-}$ & $\mathrm{CO}_{3}^{2-}$ & $\mathrm{HCO}_{3}^{-}$ & $\mathrm{RAS}^{-}$ \\
\hline & $\mathrm{dS} \mathrm{m}{ }^{-1}$ & & \multicolumn{2}{c}{---------------------- $\mathrm{mmol}_{\mathrm{c}} \mathrm{L}^{-1}$} & \\
\hline 8,31 & 0,52 & 2,07 & 0,91 & 2,87 & 0,51 & 3,91 & 0,23 & 1,78 & 0,70 \\
\hline
\end{tabular}

CE: condutividade elétrica; $\mathrm{pH}$ : potencial de hidrogênio; $\mathrm{K}^{+}$: potássio; $\mathrm{Na}^{+}$: sódio; $\mathrm{Ca}^{2+}$ : Cálcio; $\mathrm{Mg}^{2+}$ : magnésio; $\mathrm{Cl}^{-}$: cloro; $\mathrm{CO}_{3}{ }^{2-}$ : carbonato; $\mathrm{HCO}_{3}^{-}$: bicarbonato; RAS: razão de adsorção de sódio.

Para o desenvolvimento do experimento, construiu-se uma estrutura formada por 30 calhas de PVC, com as dimensões $(1,50 \times 0,10 \mathrm{x}$ $0,10 \mathrm{~m}$, em comprimento, largura e profundidade, respectivamente) montadas sobre telhas de amianto suspensas sobre cavaletes de madeira, com altura de $0,65 \mathrm{~m}$ acima do solo.

As calhas foram preenchidas com fibra de coco e em seguida irrigadas com água coletada no sistema de abastecimento da UFERSA. Em cada parcela experimental (calha), foram abertas quinze covas, nas quais foram semeadas cinco sementes de rúcula, e cinco dias após a emergência, realizou-se o desbaste deixando-se as duas plantas mais vigorosas em cada cova.
As irrigações foram realizadas duas vezes ao dia no período compreendido entre a semeadura e o desbaste, utilizando um regador manual. Após o desbaste iniciaram as fertirrigações utilizando soluções nutritivas, de acordo com cada tratamento, através do sistema de irrigação.

As quantidades de fertilizantes utilizadas no preparo das soluções nutritivas, bem como suas respectivas condutividades elétricas, são apresentadas na Tabela 2. A composição de nutrientes das soluções nutritivas seguiu a recomendação de Furlani et al. (1999) para o cultivo hidropônico de hortaliças folhosas. Após o preparo das soluções nutritivas realizava-se a 
Tabela 2. Quantidades fertilizantes, cloreto de sódio e condutividade elétrica das soluções nutritivas utilizadas no experimento.

\begin{tabular}{lllll}
\hline \multirow{2}{*}{ Fertilizantes } & \multicolumn{4}{c}{ Soluções nutritivas } \\
\cline { 2 - 5 } & $\mathrm{S} 1$ & $\mathrm{~S} 2$ & $\mathrm{~S} 3$ & $\mathrm{~S} 4$ \\
\hline Fosfato monoamônico $\left(\mathrm{mg} \mathrm{L}^{-1}\right)$ & 150 & 150 & 150 & 150 \\
Nitrato de cálcio $\left(\mathrm{mg} \mathrm{L}^{-1}\right)$ & 750 & 750 & 750 & 750 \\
Nitrato de potássio $\left(\mathrm{mg} \mathrm{L}^{-1}\right)$ & 500 & 500 & 750 & 1000 \\
Sulfato de magnésio $\left(\mathrm{mg} \mathrm{L}^{-1}\right)$ & 400 & 400 & 400 & 400 \\
Rexolin® $\left(\mathrm{mg} \mathrm{L}^{-1}\right)$ & 30 & 30 & 30 & 30 \\
\hline $\mathrm{NaCl}\left(\mathrm{mg} \mathrm{L}^{-1}\right)$ & 0 & 1900 & 1900 & 1900 \\
$\left.\mathrm{CE}(\mathrm{dS} \mathrm{m})^{-1}\right)^{*}$ & 2,1 & $5,3^{*}$ & 5,5 & 5,9 \\
\hline
\end{tabular}

Rexolin® - Composto de micronutrientes; S1 - Solução nutritiva padrão; S2 - Solução nutritiva padrão + $\mathrm{NaCl}\left(3,5 \mathrm{dS} \mathrm{m}{ }^{-1}\right)$; $\mathrm{S} 3-\mathrm{S} 2+50 \%$ de $\mathrm{KNO}_{3} ; \mathrm{S} 4-\mathrm{S} 2+100 \%$ de $\mathrm{KNO}_{3} .{ }^{*}$ condutividades elétricas após o preparo das soluções nutritivas.

O sistema de irrigação foi composto por quatro reservatórios de PVC (60 L), linhas laterais de $16 \mathrm{~mm}$ e emissores do tipo microtubos com $0,8 \mathrm{~mm}$ de diâmetro interno de $10 \mathrm{~cm}$ de comprimento. A injeção da solução nutritiva foi realizada utilizando uma eletrobomba de circulação Metalcorte/Eberle, autoventilada, modelo EBD250076 (acionada por motor monofásico, $210 \mathrm{~V}$ de tensão, $60 \mathrm{~Hz}$ de frequência).

O controle da aplicação da solução nutritiva foi realizado utilizando um temporizador (Timer Digital) com capacidade para oito programações diárias, inicialmente com seis irrigações, no período entre $07 \mathrm{~h} 00 \mathrm{~min}$ às 17h:00min, tendo duração de 10 segundos cada. Após 20 dias da semeadura aumentou o tempo de cada evento de irrigação para 20 segundos. A frequência e o tempo de irrigação para cada evento foram suficientes para promover a drenagem da solução nutritiva, de modo a garantir a elevação da umidade do substrato à máxima capacidade de armazenamento de água.

As plantas foram coletadas aos 37 dias após a semeadura cortando-se rente ao substrato, coletando 20 plantas por parcela para serem analisadas quanto as seguintes variáveis: altura, número de folhas, área foliar, massa fresca da parte aérea, massa seca da parte aérea, área foliar específica e suculência foliar.

A altura foi determinada utilizando uma régua graduada $(\mathrm{cm})$, sendo realizado no momento da coleta e considerando a distância entre o colo da planta e o ápice da maior folha.

O número de folhas por planta foi determinado logo após a coleta, considerando apenas as folhas que apresentaram mais de $70 \%$ de coloração verde e maiores de $3,0 \mathrm{~cm}$ de comprimento, desprezando-se as amareladas e/ou secas.

A área foliar foi determinada pelo método dos discos foliares utilizando um anel volumétrico com diâmetro interno de $2,5 \mathrm{~cm}$ $\left(4,9 \mathrm{~cm}^{2}\right)$, coletando-se 20 discos foliares por parcela.

Os discos foliares foram acondicionados em sacos de papel e secos em estufa com circulação forçada de ar em temperatura de 65 ${ }^{\circ} \mathrm{C}$ até atingir peso constante. A partir dos valores da área dos discos, da massa seca dos discos e das folhas, determinou-se a área foliar da planta utilizando a equação 1 (BENINCASA, 2003). 


$$
\mathrm{AF}=\frac{\mathrm{AD} \times \mathrm{MSF}}{\frac{\mathrm{MSD}}{\mathrm{N}}}
$$

Em que:

$\mathrm{AF}$ - área foliar, $\mathrm{cm}^{2}$;

$\mathrm{AD}$ - área total dos discos, $\mathrm{cm}^{2}$;

MSF - massa seca de folhas (folha + discos), g;

MSD - massa seca dos discos foliares, $\mathrm{g}$;

$\mathrm{N}$ - número de discos utilizados na parcela.

A massa fresca das plantas foi determinada logo após a coleta, utilizando-se uma balança digital de precisão. Para

$$
\mathrm{AFE}=\frac{\mathrm{AF}}{\mathrm{MSF}}
$$

Em que:

$\mathrm{AFE}$ - área foliar específica, $\mathrm{cm}^{2} \mathrm{~g}^{-1} \mathrm{MSF}$;

$\mathrm{AF}$ - área foliar, $\mathrm{cm}^{2}$

MSF - massa seca de folhas, g;

Índice de área foliar y su quantificar a massa seca, as plantas foram acondicionadas em sacos de papel previamente identificados e postas para secagem em estufa com circulação forçada de ar, na temperatura de $65^{\circ} \mathrm{C}( \pm 1)$. As plantas permaneceram na estufa até que atingiram peso constante. Em seguida foram pesadas em balança digital de precisão $(0,01 \mathrm{~g})$. Área foliar específica foi determinada pela razão entre a área foliar e a massa seca de folhas, equação 2 (BENINCASA, 2003).

$$
\mathrm{SF}=\frac{(\mathrm{MFF}-\mathrm{MSF})}{\mathrm{AF}}
$$

influencia em la capacidade fotossintética del cafeto. A suculência foliar foi determinada a partir da razão entre o teor de água na folha e área foliar, equação 3 (DELF, 1912).
Em que:

$\mathrm{SF}$ - suculência foliar, $\mathrm{g} \mathrm{H}_{2} \mathrm{O} \mathrm{cm}{ }^{2}$;

MFF - massa fresca de folhas, $g$;

MSF - massa seca de folhas, $\mathrm{g}$;

$\mathrm{AF}$ - área foliar, $\mathrm{cm}^{2}$ planta $^{-1}$.

Os dados obtidos foram submetidos à análise de variância através do teste $F$, realizando o desdobramento dos fatores sempre que foi verificado efeito significativo da interação. As variáveis que apresentaram resposta significativa foram comparadas entre si pelo teste de comparação de médias (Tukey,
5\%). As análises estatísticas foram realizadas utilizando o sistema computacional de análise de variância, Sisvar 5.3 (FERREIRA, 2011).

\section{RESULTADOS E DISCUSSÃO}

A análise dos dados mostrou que houve efeito significativo da interação entre os fatores solução nutritiva e cultivares para os parâmetros área foliar (AF), massa fresca da parte aérea (MFPA), massa seca da parte aérea (MSPA) e suculência foliar (SF) ao nível de $1 \%$ de 
significância. Além disso, houve efeito isolado significativo $(\alpha<0,01)$ do fator solução nutritiva para todas as variáveis analisadas altura de plantas (ALT), número de folhas (NF), AF, MFPA e MSPA, e ao nível de $5 \%$ para as variáveis a área foliar específica (AFE) e SF. Quanto ao efeito isolado das cultivares, verificou-se resposta significativo $(\alpha<0,01)$ apenas para as variáveis AF, MFPA e MSPA (Tabela 3).

Tabela 3. Resumo da análise de variância (quadrados médios) para altura da planta (ALT), número de folhas (NF), área foliar (AF), massa fresca da parte aérea (MFPA), massa seca da parte aérea (MSPA) área foliar específica (AFE) e suculência foliar (SF) de rúcula submetida a estresse salino e doses de nitrato e potássio.

\begin{tabular}{cccccc}
\hline Variáveis & $\begin{array}{c}\text { Soluções nutritivas } \\
(\mathrm{SN})\end{array}$ & Cultivares $(\mathrm{C})$ & $\begin{array}{c}\text { Interação } \\
\text { SN x C }\end{array}$ & Resíduo & CV \\
\hline ALT & $16,94^{* *}$ & $1,62^{\mathrm{ns}}$ & $5,47^{\mathrm{ns}}$ & 1,7 & 9,12 \\
$\mathrm{NF}$ & $1,96^{* *}$ & $0,12^{\mathrm{ns}}$ & $0,57^{\mathrm{ns}}$ & 0,32 & 7,16 \\
AF & $52247,04^{* *}$ & $9477,51^{* *}$ & $13189,47^{* *}$ & 888,53 & 9,57 \\
MFPA & $82,34^{* *}$ & $43,78^{* *}$ & $18,86^{* *}$ & 3,86 & 10,56 \\
MSPA & $0,46013^{* *}$ & $0,20646^{* *}$ & $0,19185^{* *}$ & 0,01556 & 10,63 \\
AFE & $1528,61^{*}$ & $958,94^{\mathrm{ns}}$ & $831,70^{\mathrm{ns}}$ & 387,47 & 7,44 \\
SF & $0,0025^{*}$ & $0,0003^{\mathrm{ns}}$ & $0,00027^{* *}$ & 0,00003 & 10,6 \\
\hline
\end{tabular}

*-Significativo a 5\% de significância, ** -significativo a 1\% de significância, ns - não significativo pelo teste F.

Na Tabela 4 são apresentados os resultados obtidos para as variáveis altura de plantas, número de folhas e área foliar específica, na qual verificase que houve efeito significativo apenas para as soluções nutritivas.

Tabela 4. Valores médios para altura de plantas, número de folhas e área foliar específica em cultivares de rúcula fertigadas com diferentes soluções nutritiva.

\begin{tabular}{cccc}
\hline Soluções nutritivas & $\begin{array}{c}\text { Altura } \\
(\mathrm{cm})\end{array}$ & Número de folhas & $\begin{array}{c}\text { Área foliar específica } \\
\left(\mathrm{cm}^{2} \mathrm{~g}^{-1} \mathrm{MSF}\right)\end{array}$ \\
\hline S1 & $27,84 \mathrm{a}$ & $8,57 \mathrm{a}$ & $286,30 \mathrm{a}$ \\
S2 & $22,39 \mathrm{~b}$ & $7,26 \mathrm{~b}$ & $259,95 \mathrm{ab}$ \\
S3 & $23,83 \mathrm{~b}$ & $7,41 \mathrm{~b}$ & $266,24 \mathrm{ab}$ \\
S4 & $25,15 \mathrm{ab}$ & $8,07 \mathrm{ab}$ & $249,36 \mathrm{~b}$ \\
\hline Cultivares & & & \\
Cultivada & $25,79 \mathrm{a}$ & $8,02 \mathrm{a}$ & $258,39 \mathrm{a}$ \\
Folha Larga & $25,31 \mathrm{a}$ & $7,88 \mathrm{a}$ & $271,03 \mathrm{a}$ \\
\hline
\end{tabular}

* Médias seguidas pelas mesmas letras nas colunas não diferem entre si pelo teste de Tukey a 5\% de significância $\mathrm{S} 1$ - Solução nutritiva padrão (SNP), $\mathrm{S} 2-\mathrm{SNP}+\mathrm{NaCl}\left(3,5 \mathrm{dS} \mathrm{m}^{-1}\right), \mathrm{S} 3-\mathrm{SNP}+\mathrm{NaCl}\left(3,5 \mathrm{dS} \mathrm{m}^{-1}\right)+50 \%$ de $\mathrm{KNO}_{3}, \mathrm{~S} 4-$ $\mathrm{SNP}+\mathrm{NaCl}\left(3,5 \mathrm{dS} \mathrm{m}^{-1}\right)+100 \%$ de $\mathrm{KNO}_{3}$

A altura das plantas foi reduzida quando as mesmas foram irrigadas com solução salina (S2), bem como quando se utilizou solução salinizada com dose extra de $50 \%$ de $\mathrm{KNO}_{3}$ (S3), ocorrendo perdas de 19,6 e 14,4\%, respectivamente em comparação com os valores obtidos nas plantas fertirrigadas com solução nutritiva padrão (S1). No entanto, ao adicionar $100 \%$ de $\mathrm{KNO}_{3}$ (S4) verificou-se que ocorreu resposta positiva, reduzindo o efeito da salinidade sobre esta variável, não diferindo estatisticamente da solução padrão. Tais 


\section{CULTIVO DE RÚCULA EM FIBRA DE COCO UTILIZANDO SOLUÇÃO NUTRITIVA SALINIZADA ENRIQUECIDA COM NITRATO DE POTÁSSIO}

resultados mostraram que o enriquecimento da solução nutritiva com nitrato de potássio foi eficiente para amenizar o efeito da salinidade sobre a altura das plantas (Tabela 4).

Assim, verifica-se que, apesar da solução S4 apresentar maior condutividade elétrica, o aumento no número de folhas deve-se ao efeito positivo do nitrogênio e do potássio sobre a emissão foliar, conforme observado por (REZENDE et al., 2017).

Outros autores também verificaram redução na altura de plantas de rúcula com o uso de água salina, seja no preparo da solução nutritiva no cultivo em substrato (OLIVEIRA et al., 2013), em sistema NFT (SILVA et al., 2012).

O número de folhas foi reduzido com o uso de solução salina de forma semelhante para ambas as cultivares, apresentando redução média de 18,04\% em comparação com as plantas cultivadas com a solução S1 (padrão). Além disso, o enriquecimento da solução salina com $\mathrm{KNO}_{3}$ proporcionou aumento o número de folhas (Tabela 4).

A redução do número de folhas em rúcula é uma resposta comum das plantas a salinidade, fato também observado tanto cultivo em substrato (OLIVEIRA et al., 2013) quanto em sistema hidropônico NFT (SILVA et al., 2012).

A área foliar específica das plantas foi reduzida quando as mesmas foram irrigadas com solução nutritiva salinizada, ocorrendo perdas de 9,2; 7,0 e 12,9\%, nas soluções S2, S3 e S4, respectivamente, apesar de não ter ocorrido diferença significativa entre as soluções S1, S2 e S3. Tais resultados mostraram que o enriquecimento da solução nutritiva com nitrato de potássio não foi suficiente para amenizar o efeito da salinidade sobre a área foliar específica das plantas, provocando, inclusive, sua redução quando se utilizou maior dose extra de $\mathrm{KNO}_{3}$ (Tabela 4).

A área foliar específica está relacionada com a espessura do limbo foliar, de forma que, a redução nesta variável indica que o efeito da salinidade é mais severo na expansão do limbo foliar do que sobre a produção de matéria nas folhas, resultando em folhas mais grossas (OLIVEIRA et al., 2016). Essa resposta ocorreu, provavelmente, porque um dos principais efeitos da salinidade sobre as plantas é a redução na expansão foliar, que é reduzida em maior proporção que a massa seca da folha (PARIDA; DAS, 2005).

A redução na área foliar específica da rúcula observada no presente trabalho na maior dose de $\mathrm{KNO}_{3}$ pode ter ocorrido de forma indireta do fertilizante, provavelmente, em função da maior salinidade da solução nutritiva

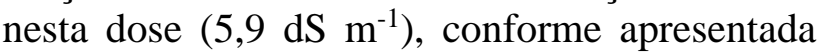
na Tabela 2 .

Com relação à área foliar das plantas, houve uma diferença significativa em relação à solução padrão e as demais soluções (S2, S3 e S4), para ambas as cultivares, no entanto, o efeito da salinidade variou de acordo com cada cultivar.

A cultivar Cultivada foi superior em $39,6 \%$ em relação a cultivar Folha Larga para o uso da solução padrão ( $\mathrm{S} 1$ ), no entanto, não diferiu nas soluções S2 e S3, e foi inferior $33,1 \%$ na solução S4 (Figura 1). 




Figura 1. Área foliar em cultivares de rúcula cultivadas em fibra de coco e fertirrigadas com diferentes soluções nutritivas.

* Médias seguidas da mesma letra, maiúsculas (cultivares) e minúsculas (soluções nutritivas) não diferem entre si pelo teste de Tukey a 5\% de significância. S1 - Solução nutritiva padrão; S2 - Solução nutritiva padrão + $\mathrm{NaCl}\left(3,5\right.$ dS m $\left.{ }^{-1}\right) ; \mathrm{S} 3-\mathrm{S} 2+$ $50 \%$ de $\mathrm{KNO}_{3} ; \mathrm{S} 4-\mathrm{S} 2+100 \%$ de $\mathrm{KNO}_{3}$

Analisando o efeito das soluções nutritivas em cada cultivar, verifica-se que a cultivar Cultivada apresentou redução com o aumento da salinidade e não apresentou resposta a adição extra de nitrato de potássio. Por outro lado, a cultivar Folha Larga, apesar de ter sua área foliar reduzida com o aumento da salinidade, apresentou resposta positiva com a adição da maior dose de potássio (S4) (Figura 1).

Efeito negativo da salinidade sobre a área foliar a rúcula cultivada em substrato também foi observado por outros autores (OLIVEIRA et al., 2013). A redução da área foliar é um importante mecanismo adaptativo de plantas cultivadas sob excesso de sais e estresse hídrico, visto que, sob tais condições, é interessante a redução na transpiração e, consequentemente, diminuição do carregamento de íons de $\mathrm{Na}^{+}$e $\mathrm{Cl}^{-}$no xilema e conservação da água nos tecidos das plantas (TAIZ; ZEIGER, 2013).

Com relação à massa fresca da parte aérea, houve diferença entre as cultivares nas soluções S1 e S2, nas quais a cultivar Cultivada foi superior à cultivar Folha Larga, em cerca de 23,1 e $44 \%$, para $\mathrm{S} 1$ e $\mathrm{S} 2$, respectivamente (Figura 2). 


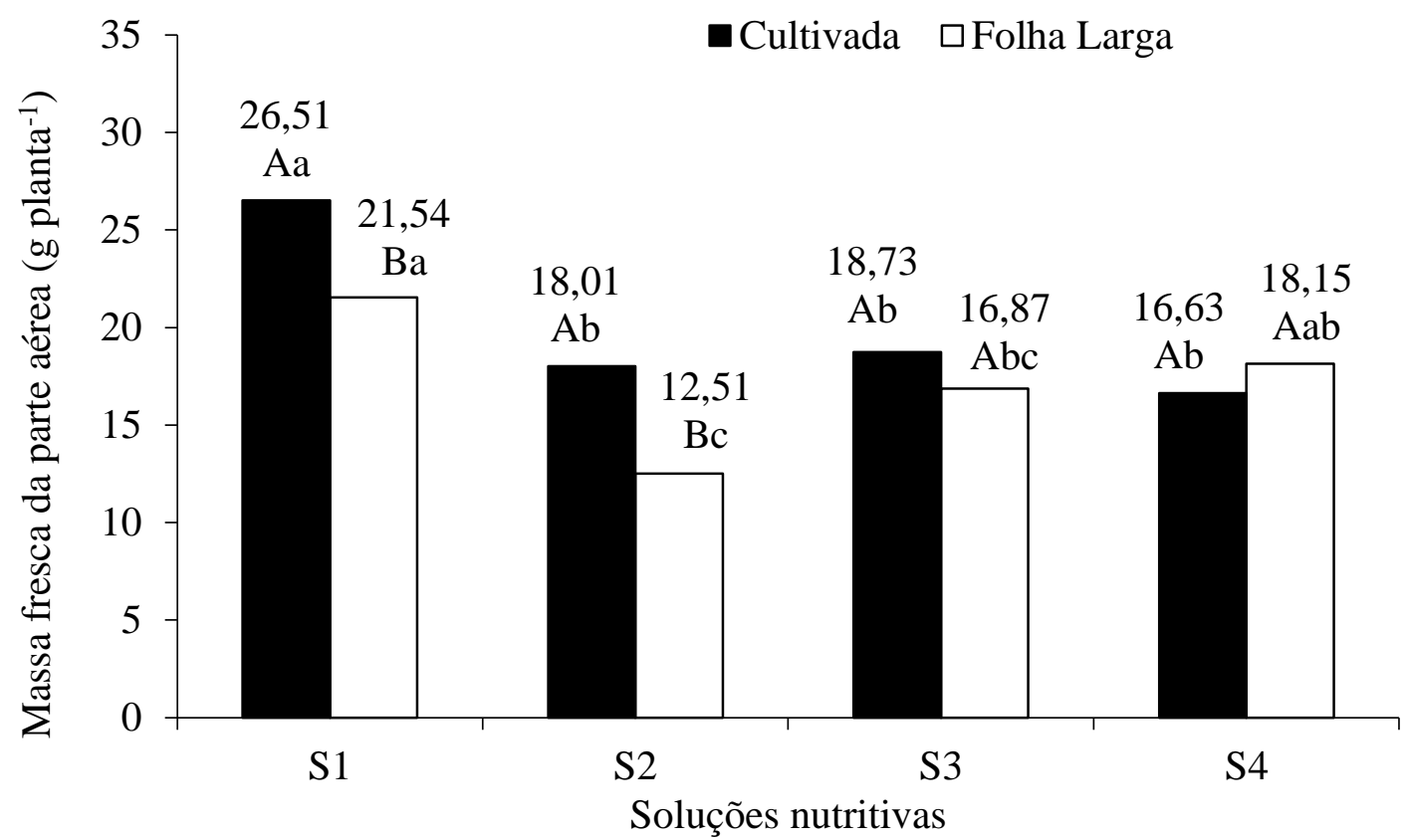

Figura 2. Massa fresca da parte aérea em cultivares de rúcula cultivadas em fibra de coco e fertigadas com diferentes soluções nutritivas.

* Médias seguidas da mesma letra, maiúsculas (cultivares) e minúsculas (soluções nutritivas) não diferem entre si pelo teste de Tukey a 5\% de significância. S1 - Solução nutritiva padrão; S2 - Solução nutritiva padrão + $\mathrm{NaCl}\left(3,5 \mathrm{dS} \mathrm{m}{ }^{-1}\right) ; \mathrm{S} 3$ - S2 + $50 \%$ de $\mathrm{KNO}_{3} ; \mathrm{S} 4-\mathrm{S} 2+100 \%$ de $\mathrm{KNO}_{3}$

Quanto ao efeito das soluções nutritivas, verificou-se que a cultivar Cultivada apresentou uma resposta negativa para o uso da solução salina (S2), ocorrendo perda de 47,2\% em relação ao valor obtida na solução $\mathrm{S} 1$, não apresentando resposta significativa para as demais soluções (S3 e S4) (Figura 2).

Para a cultivar Folha Larga, a utilização da solução salina (S2) provocou redução de $72,2 \%$ na matéria fresca da parte aérea, no entanto, ao contrário do observado para a cultivar Cultivada, a adição de $50 \%$ (S3) e $100 \%$ (S4) de $\mathrm{KNO}_{3}$ em respectivas soluções, favoreceu para o aumento da massa fresca em relação ao valor obtida na solução S2 (Figura 2).

Os resultados apresentados mostram que a cultivar Folha Larga é mais sensível à salinidade para a produção de massa fresca, confirmando os resultados apresentados por Jesus et al. (2015) e Oliveira et al. (2013). Além disso, verificou-se que existe relação entre a sensibilidade da cultivar à salinidade ao aumento na disponibilidade de $\mathrm{KNO}_{3}$.

Resposta positiva da adubação extra com $\mathrm{KNO}_{3}$ sobre a produção de rúcula ocorreu porque, segundo Viana e Kiehl (2010) o potássio estimula o aproveitamento do nitrogênio possibilitando que sua absorção, assimilação, nutrição e, consequentemente a sua produtividade, sejam aumentadas. NurzynskaWierdak (2009) também observou, em rúculas, que o aumento das doses de potássio contribuiu para o aumento significativo da produção de matéria fresca.

Os baixos níveis de potássio, causado pelo aumento na concentração de sódio na solução nutritiva, podem causar desregulação do mecanismo de abertura e fechamento dos estômatos, como também comprometer a ativação da enzima carboxilativa do ciclo de Calvin na fase bioquímica da fotossíntese, ocasionando limitações fotossintéticas e 
consequentemente menores crescimentos de planta (PRADO, 2008).

Com relação à massa seca da parte aérea, houve diferença significativa entre as cultivares em todas as soluções nutritivas, sendo a cultivar
Cultivada superior à Folha Larga em 39,1; 32,1 e $30,7 \%$ nas soluções S1, S2 e S3, respectivamente. Por outro lado, a cultivar Folha Larga foi superior à Cultivada na solução S4 em $31,9 \%$ (Figura 3).

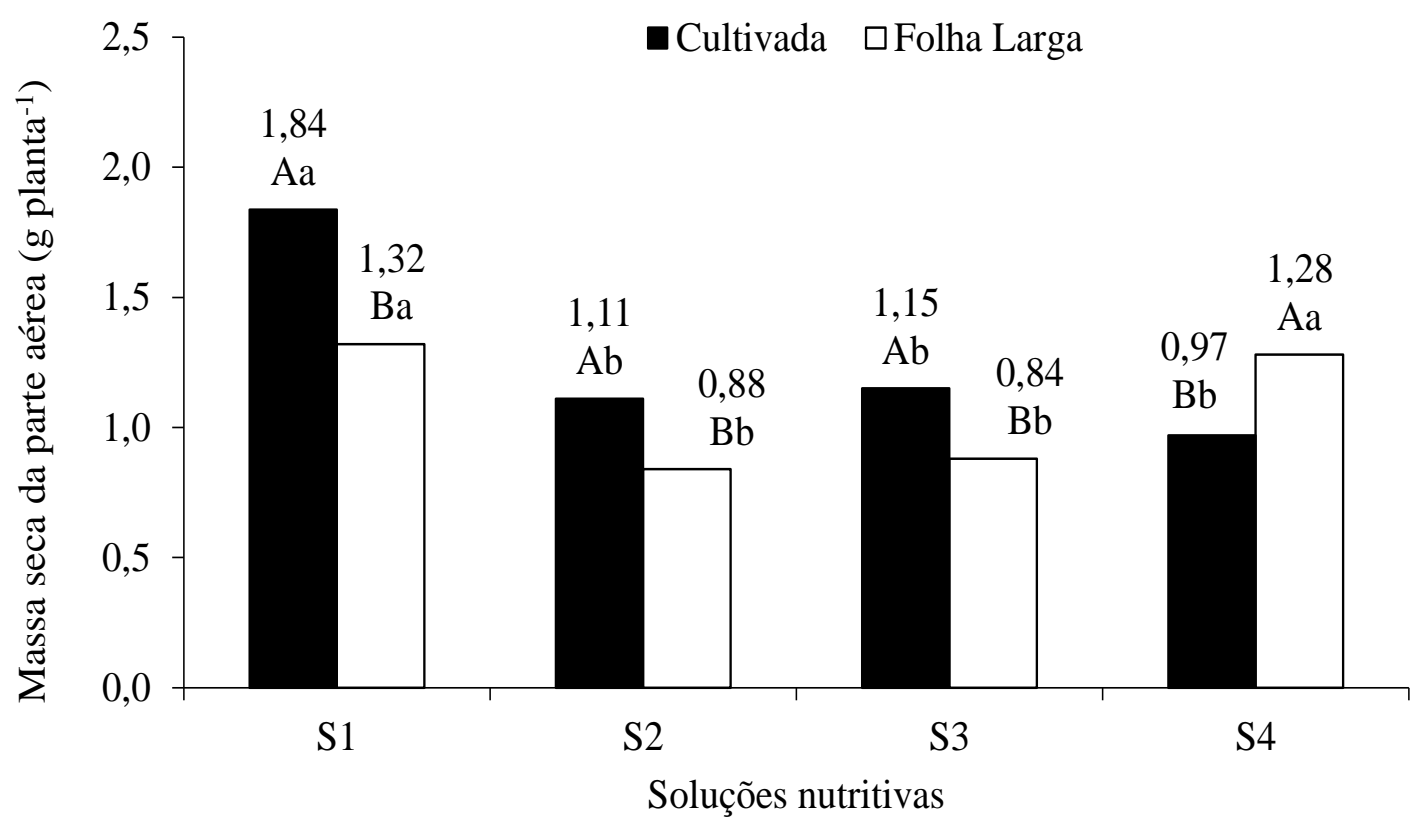

Figura 3. Massa seca da parte aérea em cultivares de rúcula cultivadas em fibra de coco e fertigadas com diferentes soluções nutritivas.

* Médias seguidas da mesma letra, maiúsculas (cultivares) e minúsculas (soluções nutritivas) não diferem entre si pelo teste de Tukey a 5\% de significância. S1 - Solução nutritiva padrão; S2 - Solução nutritiva padrão + $\mathrm{NaCl}\left(3,5\right.$ dS m $\left.{ }^{-1}\right) ; \mathrm{S} 3-\mathrm{S} 2+$ $50 \%$ de $\mathrm{KNO}_{3} ; \mathrm{S} 4-\mathrm{S} 2+100 \%$ de $\mathrm{KNO}_{3}$

Avaliando o efeito das soluções nutritivas sobre a massa seca da parte aérea sobre cada cultivar, verifica-se que, para cultivar Cultivada, o uso de solução salina reduziu a produção de biomassa, independentemente da aplicação extra de $\mathrm{KNO}_{3}$, ocorrendo perdas de 39,6; 37,4 e 47,2\%, nas soluções S2, S3 e S4, respectivamente. Para cultivar Folha Larga, o uso de água salina no preparo da solução nutritiva provocou redução na massa seca de $36,4 \%$ (S2) e 33,3\% (S3), entretanto, ao adicionar $100 \%$ de $\mathrm{KNO}_{3}$, houve resposta positiva, de forma a inibir o efeito da salinidade (Figura 3).

Desta forma, verifica-se que, para cultivar Cultivada, a aplicação extra de 50 e $100 \%$ de
$\mathrm{KNO}_{3}$ não foi suficiente para inibir o efeito salino sobre o crescimento das plantas. Verificase ainda na Figura 3, que a cultivar Folha Larga apresentou menor redução na produção de matéria seca que a cultivar Cultivada.

$\mathrm{Na}$ literatura existem vários relatos de estudos, com mesmas cultivares utilizadas neste experimento, que mostram redução na massa seca de rúcula em resposta ao estresse salino, seja em cultivo hidropônico NFT (SILVA et al., 2011; JESUS et al., 2015) ou em substrato (OLIVEIRA et al., 2013; SANTOS et al., 2012).

A redução da biomassa e seca está em plantas submetidas ao estresse salino está relacionada ao efeito osmótico da salinidade, e ao suprimento inadequado de nutrientes devido 


\section{CULTIVO DE RÚCULA EM FIBRA DE COCO UTILIZANDO SOLUÇÃO NUTRITIVA SALINIZADA ENRIQUECIDA COM NITRATO DE POTÁSSIO}

a um desequilíbrio iônico provocado pelo excesso de íons $\mathrm{Na}^{+}$e $\mathrm{Cl}^{-}$(TESTER; DAVENPORT, 2003). Além disso, o potássio aumenta a massa seca e fresca da parte aérea de plantas de rúcula devido sua contribuição nas diversas funções que exerce na planta, principalmente na abertura e fechamento dos estômatos (PORTO et al., 2013).

$\mathrm{O}$ uso de solução nutritiva salina provocou aumento na suculência foliar da cultivar
Cultivada, e não ocorreu efeito significativo da de 50 e $100 \%$ de $\mathrm{KNO}_{3}$. Para cultivar Folha Larga, também ocorreu aumento da suculência com o uso de solução salina, no entanto, o incremento extra de $\mathrm{KNO}_{3}$ provocou redução nesta variável, apesar de não ocorrer diferença as soluções S3 e S4 (Figura 4).

- Cultivada $\square$ Folha Larga

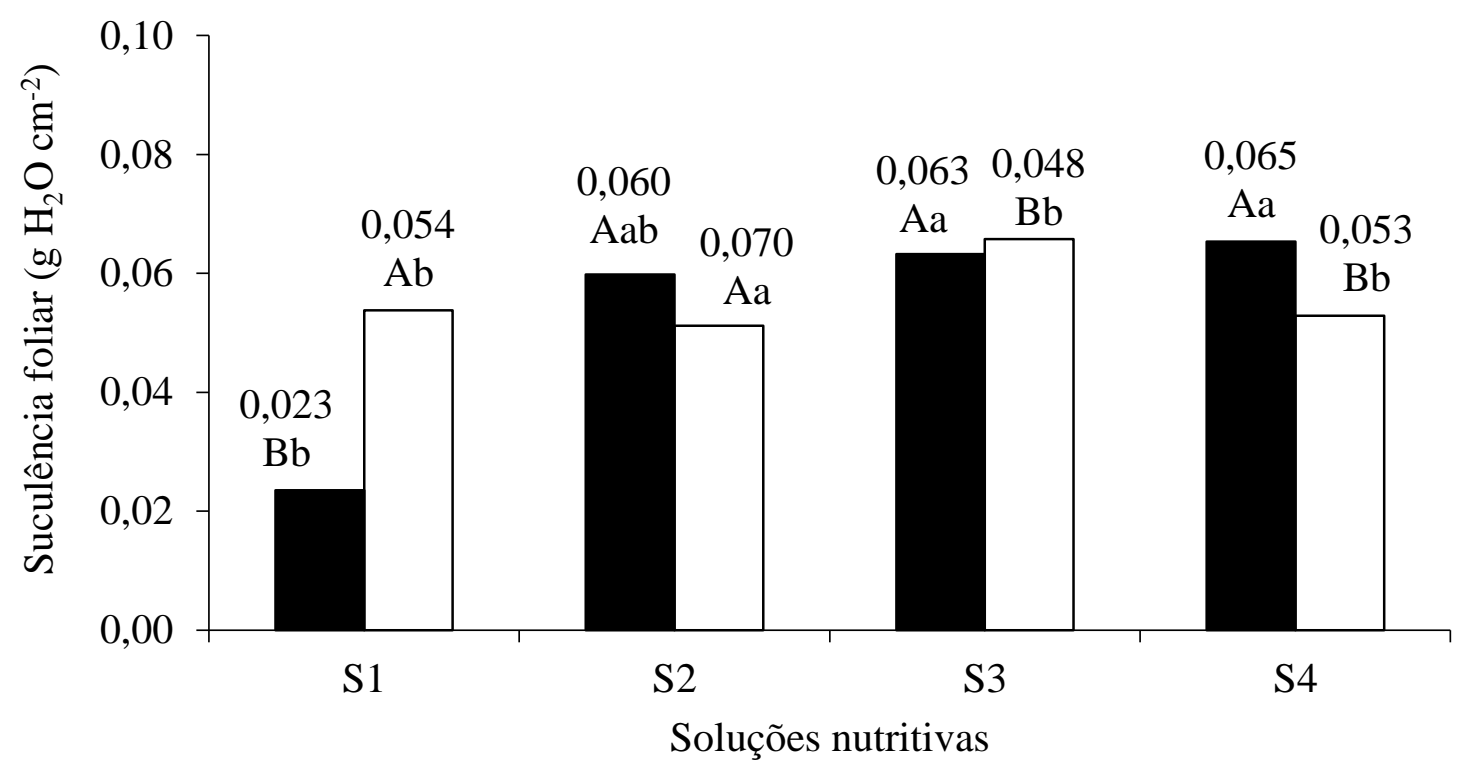

Figura 4. Suculência foliar em cultivares de rúcula cultivadas em fibra de coco e fertigadas com diferentes soluções nutritivas.

* Médias seguidas da mesma letra, maiúsculas (cultivares) e minúsculas (soluções nutritivas) não diferem entre si pelo teste de Tukey a 5\% de significância. S1 - Solução nutritiva padrão; S2 - Solução nutritiva padrão + $\mathrm{NaCl}\left(3,5 \mathrm{dS} \mathrm{m}^{-1}\right) ; \mathrm{S} 3$ - S2 + $50 \%$ de $\mathrm{KNO}_{3} ; \mathrm{S} 4-\mathrm{S} 2+100 \%$ de $\mathrm{KNO}_{3}$

Analisando as cultivares, verifica-se que a cultivar Folha Larga apresentou uma maior suculência foliar em relação cultivada ao uso da solução $\mathrm{S} 1$, porém não diferiram entre si na presença das soluções S2, por outro lado, a cultivar Cultivada foi superior nas soluções S3 e S4 (Figura 4).

Esses resultados demostram que a cultivar Cultivada apresentou menor teor de água no tecido foliar na ausência de estresse salino, no entanto, a mesma aumentou a suculência foliar como alternativa para ajuste osmótico através da absorção, transporte e acúmulo de íons nos tecidos foliares, aumentar a tolerância à salinidade (SILVA et al., 2009; ALDESUQUY et al., 2012).

Em estudo desenvolvido por Oliveira et al. (2013) utilizando as mesmas cultivares deste utilizadas neste trabalho, os autores constataram que a cultivar Folha Larga apresentou melhor suculência foliar em relação a cultivar Cultivada, assemelhando-se, em parte, com os 
resultados apresentado no presente trabalho. Estes resultados mostram que o aumento da concentração de $\mathrm{KNO}_{3}$ não foi eficiente para manter a suculência foliar na cultivar Folha Larga sob estresse salino, e não alterou a resposta da cultivar Cultivada à salinidade.

De forma geral, a cultivar Folha Larga apresentou menor tolerância ao estresse salino, bem como, apresentou maior resposta a aplicação extra de $\mathrm{KNO}_{3}$. De acordo com Moons et al. (1995), cultivares de plantas mais tolerantes apresentam maior suculência nos tecidos da parte aérea, conforme observado neste trabalho.

O aumento da suculência foliar induzido pelo $\mathrm{NaCl}$ é indicativo de ter ocorrido um efetivo ajustamento osmótico em plantas com estresse (MARTÍNEZ et al., 2004). Além disso, a suculência permite a regulação da concentração de sais nos tecidos foliares permitindo a hidratação das folhas em condição de baixa disponibilidade de água, e depende diretamente da absorção, transporte e acúmulo de íons nos tecidos foliares, podendo contribuir para reduzir o efeito dos sais sobre o crescimento da planta (MATOS et al., 2013).

\section{CONCLUSÕES}

As duas cultivares de rúcula cultivadas em fibra de coco foram afetadas negativamente pelo uso de água salina no preparo da solução nutritiva, entretanto a cultivar Cultivada apresentou maior tolerância à salinidade quanto as variáveis área foliar, massa fresca da parte aérea e massa seca da parte aérea.

O enriquecimento da solução nutritiva salina com nitrato de potássio amenizou o efeito da salinidade apenas na cultivar Folha Larga, mas não interferiu na resposta da cultivar Cultivada à salinidade.

No cultivo de rúcula, cultivar Folha Larga, em fibra de coco utilizando solução salina devese aumentar a concentração de $\mathrm{KNO}_{3}$ em $100 \%$ em relação à concentração padrão.

\section{REFERÊNCIAS BIBLIOGRÁFICAS}

ALDESUQUY, H. S.; BAKA, Z. A.; ElSHEHABY, O. A.; GHANEM, H. E. Varietal differences in growth vigor, water relations, protein and nucleic acids content of two wheat varieties grown under seawater stress. Journal of Stress Physiology \& Biochemistry, v. 8, n. 1, p. 24-47, 2012.

BENINCASA, M. M. P. Análise de crescimento de plantas: noções básicas. Jaboticabal: FUNEP, 2003. 42 p.

COVA, A. M. W.; FREITAS, F. T. O.; VIANA, P. C.; RAFAEL, M. R. S.; AZEVEDO NETO, A. D.; SOARES, T. M. Content of inorganic solutes in lettuce grown with brackish water in different hydroponic systems. Revista Brasileira de Engenharia Agrícola e Ambiental, v. 21, n. 3, p. 150-155, 2017. http://dx.doi.org/10.1590/18071929/agriambi.v21n3p150-155.

DELF, E. M. Transpiration in succulent plants. Annals of Botany, v. 26, p. 409-442, 1912. https://doi.org/10.1093/oxfordjournals.aob.a089 398.

FERREIRA, D. F. Sisvar: A computer statistical analysis system. Ciência e Agrotecnologia. v. 35, n. 6, p. 1039-1042, 2011 http://dx.doi.org/10.1590/S1413-

70542011000600001.

FURLANI, P. R.; SILVEIRA， L. C. P.; BOLONHEZI, D.; FAQUIN, V. Cultivo hidropônico de plantas. Campinas: Instituto Agronômico, 1999. 52 p. (Boletim Técnico, 180).

HNILIČKOVÁ, H.; HNILIČKA, F.; MARTINKOVÁ, J.; KRAUS, K. Effects of salt stress on water status, photosynthesis and chlorophyll fluorescence of rocket. Plant, Soil 


\section{CULTIVO DE RÚCULA EM FIBRA DE COCO UTILIZANDO SOLUÇÃO NUTRITIVA SALINIZADA ENRIQUECIDA COM NITRATO DE POTÁSSIO}

and Environment, v. 63, n. 8, p. 362-367, 2017. http://dx.doi.org/10.17221/398/2017-PSE.

JESUS, G. G.; SILVA JÚNIOR, F. J.; CAMARA, T. R.; SILVA, E. F. F.; WILLADINO, L. Production of rocket under salt stress in hydroponic systems. Horticultura Brasileira, v. 33, n. 4, p. 493-497, 2015. http://dx.doi.org/10.1590/S0102-

053620150000400014 .

LIRA, R. M.; SILVA, E. F. F.; SILVA, G. F.; SANTOS, A. N.; ROLIM, M. M. Production, water consumption and nutrient content of Chinese cabbage grown hydroponically in brackish water. Revista Ciência Agronômica, v. 46, n. 3, p. 497-505, 2015. http://dx.doi.org/10.5935/1806-6690.2015003.

MARTÍNEZ, J. P.; LUTTS, S.; SCHANCK, A.; BAJJI, M.; KINET, J. M. Is osmotic adjustment required for water stress resistance in the Mediterranean shrub Atriplexhalimus L.? Journal of Plant Physiology, v. 161, n. 9, p. 1041-1051, 2004.

http://dx.doi.org/10.1016/j.jplph.2003.12.009

MATOS, F. S.; ROCHA, E. C.; CRUVINEL, C. K. L.; RIBEIRO, R. A.; RIBEIRO, R. P.; TINOCO, C. F. Desenvolvimento de mudas de pinhão-manso irrigadas com água salina. Revista Brasileira de Ciências do Solo, v. 37, n. $\quad 4, \quad$ p. $947-954, \quad 2013$. http://dx.doi.org/10.1590/S010006832013000400012.

MEDEIROS, J. F.; LISBOA, R. A.; OLIVEIRA, M; SILVA JÚNIOR, M. J. S.; ALVES, L. P. Caracterização das águas subterrâneas usadas para irrigação na área produtora de melão da Chapada do Apodi. Revista Brasileira de Engenharia Agrícola e Ambiental, v. 7, n. 3, p. 469-472, 2003. http://dx.doi.org/10.1590/ S1415-43662003000300010.
MOONS, A.; BAUW, G.; PRINSEN, E.; VAN MONTAGU, M.; VAN DER STRAETEN, D. Molecular and physiological responses to abscisic acid and salts in rates on salt sensitive and salt tolerance indica rice varieties. Plant Physiology, v. 107, n. 1, p. 177-186, 1995. NURZYNSKA-WIERDAK， R. Growth and yield of garden rocket (Eruca sativa Mill.) affected by nitrogen and potassium fertilization. Acta Scientarum Polonorum, Hortorum Cultus, v. 8, n. 4, p. 23-33, 2009.

OLIVEIRA, F. A.; MEDEIROS, J. F.; CUNHA, R. C.; SOUZA, M. W. L.; LIMA L. A. Uso de bioestimulante como agente amenizador do estresse salino na cultura do milho pipoca. Revista Ciência Agronômica, v. 47, n. 2, p. 307-315, 2016. http://dx.doi.org/10.5935/18066690.20160036 .

OLIVEIRA, F. A.; SOUZA NETA, M. L.; SILVA, R. T.; SOUZA, A. A. T.; OLIVEIRA, M. K. T.; MEDEIROS, J. F. Desempenho de cultivares de rúcula sob soluções nutritivas com diferentes salinidades. Agro@mbiente On-line, v. 7, n. 2, p. 170-178, 2013. http://dx.doi.org/10.18227/1982-

8470ragro.v7i2.940.

PARIDA, A. K.; DAS, A. B. Salt tolerance and salinity effects on plants: a review. Ecotoxicology and Environmental Safety, v. 60, n. 3, p. 324-349, 2005. https://doi.org/10.1016/j.ecoenv.2004.06.010.

PÉREZ-LÓPEZ, U.; MIRANDA-APODACA, J.; MENA-PETITE, A.; MUÑOZ-RUEDA, A. Responses of nutrient dynamics in barley seedlings to the interaction of salinity and carbon dioxide enrichment. Environmental and Experimental Botany, v. 99, n. 3, p. 86-99, 2014.

https://doi.org/10.1016/j.envexpbot.2013.11.00.

PORTO, R. A.; BONFIM-SILVA, E. M.; SOUZA, D. S. M.; CORDOVA, N. R. M.; 
POLYZEL, A. C.; SILVA, T. J. A. Adubação potássica em plantas de rúcula: produção e eficiência no uso da água. Revista Agro@mbiente On-line, v. 7, n. 1, p. 28-35, 2013, http://dx.doi.org/10.18227/1982-

8470ragro.v7i1.760.

PRADO, R. M. Nutrição de plantas. São Paulo: UNESP, 2008. 407p.

REZENDE, R.; SOUZA, R. S.; MALLER, A.; FREITAS, P. S. L.; GONÇALVES, A. C. A.; REZENDE, G. S. Produção e qualidade comercial de alface fertirrigada com nitrogênio e potássio em ambiente protegido. Revista Ceres, v. 64, n.2, p. 205-211, 2017. http://dx.doi.org/10.1590/0034737X201764020014.

SANTOS, R. S. S.; DIAS, N. S.; DUARTE, S. N.; LIMA, C. J. G. S. Uso de águas salobras na produção de rúcula cultivada em substrato de fibra de coco. Revista Caatinga, v. 25, n. 1, p. 113-118, 2012.

SILVA, A. O.; SILVA, D. J. R.; SOARES, T. M.; SILVA, E. F. F.; SANTOS, A. N.; ROLIM, M. M. Produção de rúcula em sistema hidropônico NFT utilizando água salina do Semiárido-PE e rejeito de dessalinizador. Revista Brasileira de Ciências Agrárias, v. 6, n. 1, p. 147-155, 2011. http://dx.doi.org/10.5039/agraria.v6i1a929.

SILVA, A. O.; SOARES, T. M.; SILVA, E. F. F.; SANTOS, A. N.; KLAR, A. E. Consumo hídrico da rúcula em cultivo hidropônico NFT utilizando rejeitos de dessalinizador em Ibimirim-PE. Irriga, v. 17, n. 1, p. 114-125, 2012.

https://doi.org/10.15809/irriga.2012v17n1p114.

SILVA， E. N.; SILVEIRA， J. A. G.; RODRIGUES, C. R. F.; LIMA, C. S.; VIÉGAS, R. A. Contribuição de solutos orgânicos e inorgânicos no ajustamento osmótico de pinhãomanso submetido à salinidade. Pesquisa Agropecuária Brasileira, v. 44, n. 5, p. 437445. 2009. https://doi.org/10.1590/S0100204X2009000500002.

TAIZ, L.; ZEIGER, E. Fisiologia vegetal. 5. ed. Porto Alegre: Artmed, 2013. 954 p.

TAMMAM, A. A. E.; ALHAMD, M. F. A.; HEMEDA, M. M. Study of salt tolerance in wheat (Triticum aestium L.) cultivar Banysoif L. Australian Journal of Crop Science, v.1, n.3, p.115-125, 2008.

TESTER, M., DAVENPORT, R. $\mathrm{Na}^{+}$tolerance and $\mathrm{Na}^{+}$transport in higher plants. Annals of Botany, v. 91, p. 503-527, 2003. https://doi.org/10.1093/aob/mcg058.

VIANA, E. M.; KIEHL, J. C. Doses de nitrogênio e potássio no crescimento do trigo. Bragantia, v. $69, \quad$ n. $4, \quad$ p. $975-982$, 2010. ttp://dx.doi.org/10.1590/ 0006-87052010000400024 